\title{
Tropical drought regions in global warming and EI Niño teleconnections
}

\author{
J. D. Neelin \\ Department of Atmospheric Sciences, Institute of Geophysics and Planetary Physics, University of California at \\ Los Angeles, Los Angeles, California, USA \\ C. Chou \\ Institute of Earth Sciences, Academia Sinica, Taipei, Taiwan, ROC
}

H. $\mathrm{Su}$

Department of Atmospheric Sciences, Institute of Geophysics and Planetary Physics, University of California at Los Angeles, Los Angeles, California, USA

Received 12 September 2003; revised 4 November 2003; accepted 19 November 2003; published 24 December 2003.

[1] Climate model global warming simulations predict large regional changes in tropical rainfall, including regions of drought. Qualitatively similar changes occur during El Niño interannual variability. Using an intermediate climate model, we have identified a mechanism that creates regional reductions in precipitation at the margins of convection zones during warming. In this "upped-ante mechanism", a warm troposphere increases the value of surface boundary layer moisture required for convection to occur. In regions of plentiful moisture supply, moisture simply rises to maintain precipitation, but this increases the moisture gradient relative to neighboring subsidence regions. Reductions in rainfall then result for those margins of convection zones that have strong inflow of air from the subsidence regions and less frequently meet the increased "ante" for convection. In simulations analyzed here, this new mechanism is the leading cause of tropical drought in the global warming case and is dominant in certain El Niño drought regions. INDEX TERMS: 1620 Global Change: Climate dynamics (3309); 1655 Global Change: Water cycles (1836); 1812 Hydrology: Drought; 3354 Meteorology and Atmospheric Dynamics: Precipitation (1854); 4522 Oceanography: Physical: El Nino. Citation: Neelin, J. D., C. Chou, and H. Su, Tropical drought regions in global warming and El Niño teleconnections, Geophys. Res. Lett., 30(24), 2275, doi:10.1029/2003GL018625, 2003.

\section{Introduction}

[2] Large changes of tropical rainfall on a regional basis [Allen and Ingram, 2002] occur in climate model simulations of the global warming response to anthropogenic increases in greenhouse gases [Roeckner et al., 1999; Boer et al., 2000; Hu et al., 2000; Dai et al., 2001; Williams et al., 2001; Yonetani and Gordon, 2001; Douville et al., 2002; Giorgi, 2002]. Three examples are shown in Figure 1. Despite a slight tropical mean increase in precipitation, there are substantial areas where rainfall is reduced and the magnitude of the regional changes is sufficient to have considerable human impact. Agreement among climate models on the spatial distribution of these changes is poor

Copyright 2003 by the American Geophysical Union. 0094-8276/03/2003GL018625\$05.00
[Allen and Ingram, 2002; Houghton et al., 2001], as in Figure 1. However, the presence of these changes in many models is an indicator of sensitivity of the tropical deep convection zones under global warming, and the drought regions are particularly likely to have substantial human impacts.

[3] Variations of regional tropical rainfall are also found in interannual variability [Wallace et al., 1998], such as during El Niño events (Figure 2). It is tempting to ask whether analysis of such El Niño/Southern Oscillation (ENSO) warm phase anomalies can yield insight into the global warming case. The relationship between the two cases cannot be taken for granted as a variety of mechanisms can enter. For example, interannual variations in tropical mean precipitation appear to have a different dominant mechanism than occurs in global warming [Su and Neelin, 2003]. Furthermore, the Pacific precipitation increases during El Niño depend strongly on interaction with the ocean subsurface dynamics and the effects of this on sea surface temperature. Under global warming, such interactions may occur [Boer et al., 2000; Knutson and Manabe, 1995; Meehl and Washington, 1996; Timmermann et al., 1999; Jin et al., 2001] but they are a local amplifying feedback, the initiator of changes being the global increase in the radiative heating of the troposphere by increased greenhouse gas trapping of infrared radiation. Furthermore, negative precipitation anomalies in the El Niño case occur in the remote impacts, known as teleconnections. Any argument for similarity between global warming and El Niño cases must be made through a detailed analysis of mechanism.

\section{The EI Niño Case}

[4] In both the global warming and El Niño cases, the largest changes in tropical precipitation occur within, or on the margins of, deep convection zones and therefore involve complex feedbacks with changes in convective heating, cloud-radiative heating and large-scale atmospheric dynamics. An ongoing project at UCLA has aimed at unraveling these feedbacks for the interannual variability case [Su et al., 2001; Su and Neelin, 2002]. An intermediate complexity climate model known as the QTCM [Zeng et al., 1999; Neelin and Zeng, 2000; Zeng et al., 2000] has been helpful 

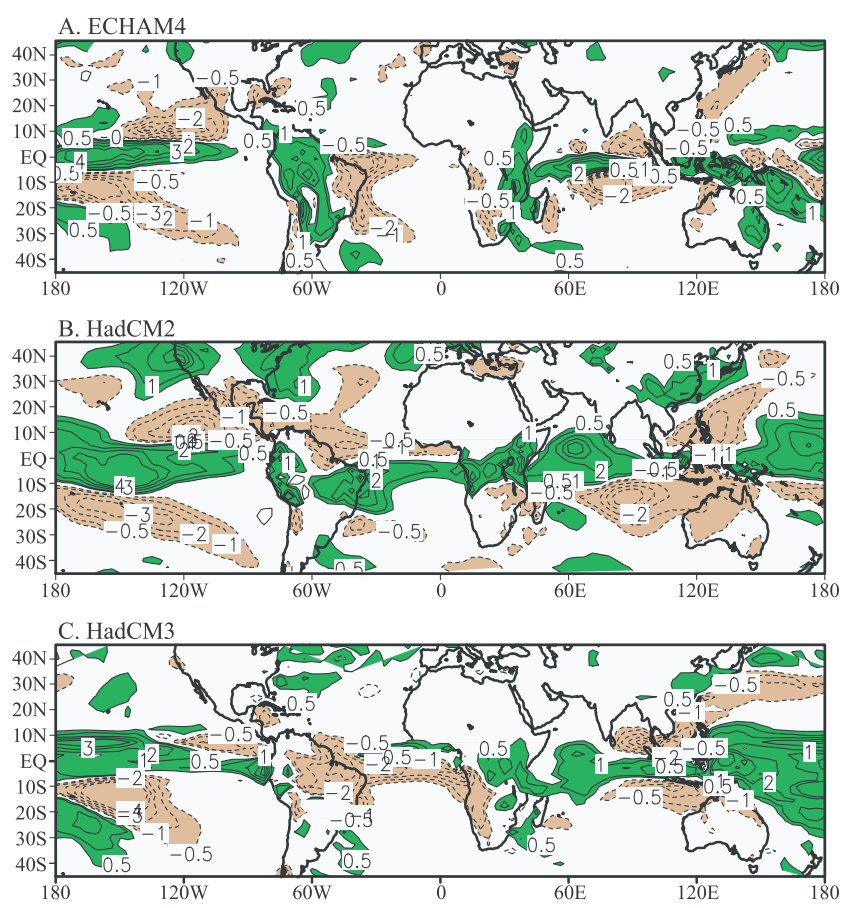

Figure 1. Precipitation anomalies $\left(\mathrm{mm} \mathrm{day}^{-1}\right)$ from three ocean-atmosphere climate models for global warming scenarios in which anthropogenic increases in greenhouse gases and sulfate aerosols have been included. Anomalies are computed for 2070-2090 relative to the 1961-1990 mean. (a) ECHAM4 [Roeckner et al., 1999], (b) HadCM2 [Mitchell et al., 1999], (c) HadCM3 [Johns et al., 2003]. Data are from the Intergovernmental Panel on Climate Change Data Distribution Center. The scenario in (c) is SRESA2 [Houghton et al., 2001] which differs slightly from the IS92a scenario in (a) and (b). Shaded for anomalies greater than $0.5 \mathrm{~mm} \mathrm{day}^{-1}$ (green/dark shading) or less than $-0.5 \mathrm{~mm} \mathrm{day}^{-1}$ (brown/light shading).

in these explorations because it simulates the variability in a manner consistent with general circulation models (GCMs) but it is much easier to analyze feedbacks in the QTCM and to conduct experiments that alter model physics for hypothesis testing. The results have been compared to observations and to GCM analysis [Su and Neelin, 2002]. Figure 2b shows the QTCM simulated precipitation anomalies for the 1997-98 El Niño. In this experiment, observed SSTs have been specified only over the main El Niño region in the eastern Pacific (with climatological SST elsewhere), so anomalies in all other regions are clearly teleconnected effects from El Niño. The simulated results compare well to observations even though smaller SST anomalies in Indian and Atlantic oceans may also have contributed to observed precipitation anomalies. In many regions the remote response to El Niño is a reduction in precipitation. The tropospheric temperature anomaly response to El Niño is a widespread warming [Wallace et al., 1998], spread outward from the Pacific by tropical wave dynamics modified by interaction with moist convection [Chiang and Sobel, 2002; Su and Neelin, 2002]. This warming is at the heart of the teleconnection, but the moist feedbacks yielding the precipitation anomalies actually differ from region to region [Su and Neelin, 2002]. Over equatorial South
America and the Atlantic intertropical convergence zone, a leading mechanism occurs associated with changes in moisture advection that proves highly relevant for the global warming case.

\section{The Global Warming Case}

[5] For a first examination of the regional moist feedbacks in the global warming case, we choose an equilibrium doubled- $\mathrm{CO}_{2}$ run with a mixed layer ocean using the standard "Q-flux" representation of ocean heat transport [Hansen et al., 1988]. This is simpler to analyze than would be a case with the additional complications of ocean dynamical feedbacks and time-dependent warming. Similar experiments in GCMs exhibit strong regional precipitation anomalies [Williams et al., 2001; Yonetani and Gordon, 2001]. Figure 2c shows the QTCM precipitation anomaly from a 40-year average under doubled- $\mathrm{CO}_{2}$ conditions minus the control climatology. Positive anomalies tend to occur in regions of strong deep convection, in a rich-getricher feedback that is analyzed elsewhere [C. Chou and J. D. Neelin, Mechanisms of global warming impacts on regional tropical precipitation, submitted to J. Clim., 2003]. While the tropical average is positive, there are substantial negative precipitation anomalies that tend to occur along
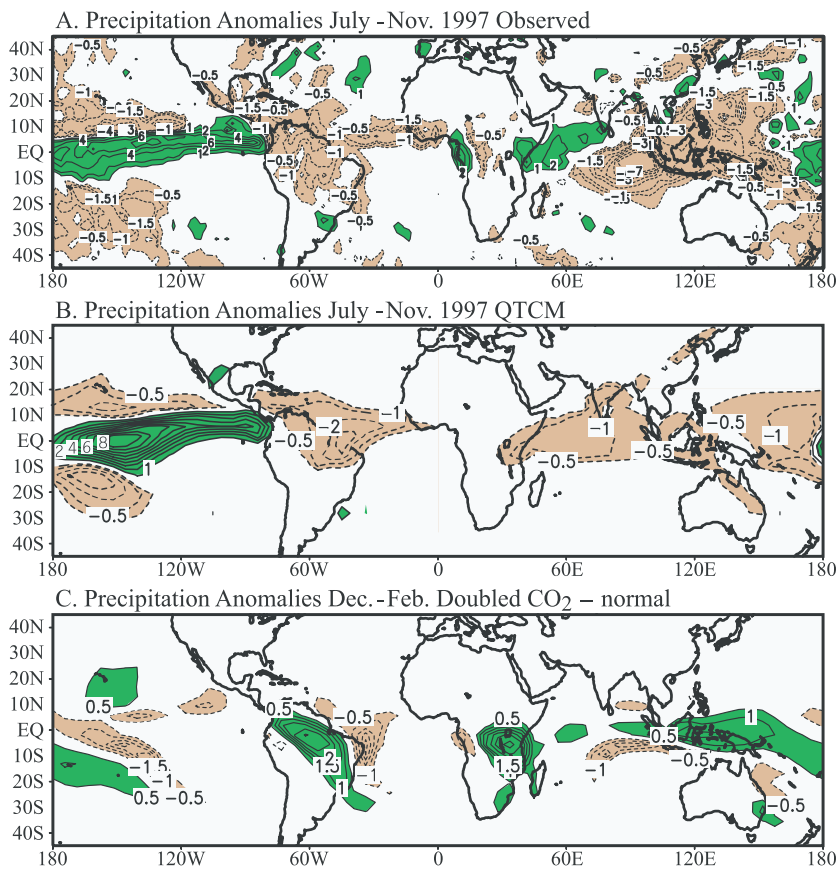

Figure 2. (a) Anomalies of observed precipitation [Xie and Arkin, 1997] from the period July-Nov 1997 during an El Niño event relative to the 1982-98 average. (b) Anomalies of precipitation from the QTCM with El Niño anomalously warm SSTs specified in the tropical Pacific during July-November 1997, relative to a control simulation with 1982-98 climatological SST. An ensemble of 10 runs from different atmospheric conditions is used. (c) Precipitation anomalies from a doubled- $\mathrm{CO}_{2}$ equilibrium response experiment with QTCM coupled to a mixed-layer ocean, relative to a normal $\mathrm{CO}_{2}$ control. A and $\mathrm{B}$ shaded green for anomalies greater than $1 \mathrm{~mm} \mathrm{day}^{-1}$, otherwise, as in Figure 1. 


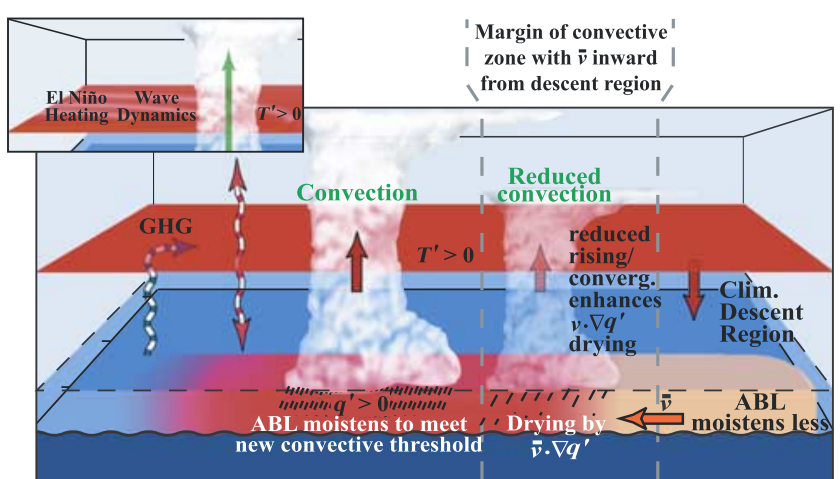

Figure 3. Schematic of the "upped-ante" mechanism for negative precipitation anomalies. For the global warming case, the tropospheric temperature warms due to increased absorption of infrared radiation (dashed curves) by greenhouse gases (GHG). For the El Niño case (inset) warming is spread from the Pacific by wave dynamics. The rest of the pathway via convective interactions is common to both. Adjustment of atmospheric boundary layer (ABL) moisture in convective regions, to meet the new convective "ante", establishes a gradient of ABL moisture anomalies $q$ ' relative to nonconvective regions. This creates a drying tendency where low-level flow $\mathbf{v}$ moves into the margin of a convective zone. Feedbacks reducing upward motion and low-level convergence enhance this drying tendency.

some margins of the convection zones, much as in the ECHAM4 and HadCM3 GCMs of Figure 1, although slightly weaker. These drought regions are all associated with changes in moisture advection $\mathbf{v} \cdot \nabla q$, i.e., horizontal wind $\mathbf{v}$ acting on gradients of moisture $q$. Both the SST and tropospheric temperature anomalies are relatively constant in space across the tropics and do not alone yield insight into the mechanisms for the strong spatial structure in the precipitation signal.

\section{The Upped-ante Mechanism}

[6] Analysis of the model moisture and moist static energy budgets indicates several mechanisms that contribute to precipitation anomalies in the El Niño case [ $\mathrm{Su}$ and Neelin, 2002; H. Su and J. D. Neelin, in preparation, 2003]. Similar analysis shows that one of these mechanisms applies to essentially all drought regions in the doubled- $\mathrm{CO}_{2}$ case (C. Chou and J. D. Neelin, submitted to J. Clim., 2003). We term this the "upped-ante mechanism" (Figure 3). Tropospheric temperature is warm in the affected region in both cases. In the El Niño case, the warming is teleconnected from the neighboring Pacific [Wallace et al., 1998]. In the global warming case it is induced by increased absorption of infrared radiation [Tett et al., 1996]. Deep convection tends to occur when a parcel of cloud updraft air from the atmospheric boundary layer (ABL) is warmer than the ambient sounding in the free troposphere. When the troposphere is warmed, ABL air must be moister for convection to occur [Chiang and Sobel, 2002]. For time averages, as here, the tropospheric temperature does not provide a precise threshold behavior, but in a poker analogy, one might say it "ups the ante" for the amount of ABL moisture a region must have to continue to compete with neighboring regions for convection. In the middle of a convergence zone, where moisture supply is plentiful, meeting this increased ante is not a barrier and convection continues and even tends to be enhanced by the increased moisture in the air being converged. However, on certain margins of the convection zone where there is a strong lowlevel flow coming from a climatologically non-precipitating region, the increased ante can be a significant barrier. The balances governing $\mathrm{ABL}$ moisture in a non-precipitating region (e.g., divergence versus evaporation) yield smaller increases in moisture than in precipitating regions in the global warming case (and can even have negative moisture anomalies in the El Niño case). This inflow of less moist air into a region that ought to have a higher $\mathrm{ABL}$ moisture to convect produces a balance where precipitation is on average reduced. In addition to the direct effect of this drying, moist static energy budget balances (C. Chou and J. D. Neelin, submitted to J. Clim., 2003) imply a reduction in large-scale rising motion in this region. Associated reductions in moisture low-level convergence provide an amplification of the drought.

\section{Tests of the Mechanism}

[7] Deducing mechanisms involving multiple feedbacks from diagnostics of model runs is notoriously challenging so we devised numerical experiments, intervening in the physics of the QTCM to suppress a key piece of the hypothesized pathway (Figure 4). Specifically, moisture advection $\mathbf{v} \cdot \nabla q$ is prescribed to remain at its climatological value. For the El Niño case (Figure 4a), the negative precipitation anomalies over South America are greatly reduced. Over the Atlantic intertropical convergence zone, anomalies are impacted but other mechanisms also continue to act, such as reduction of evaporation as moisture increases toward the increased threshold for convection [Su and Neelin, 2002]. For the global warming case
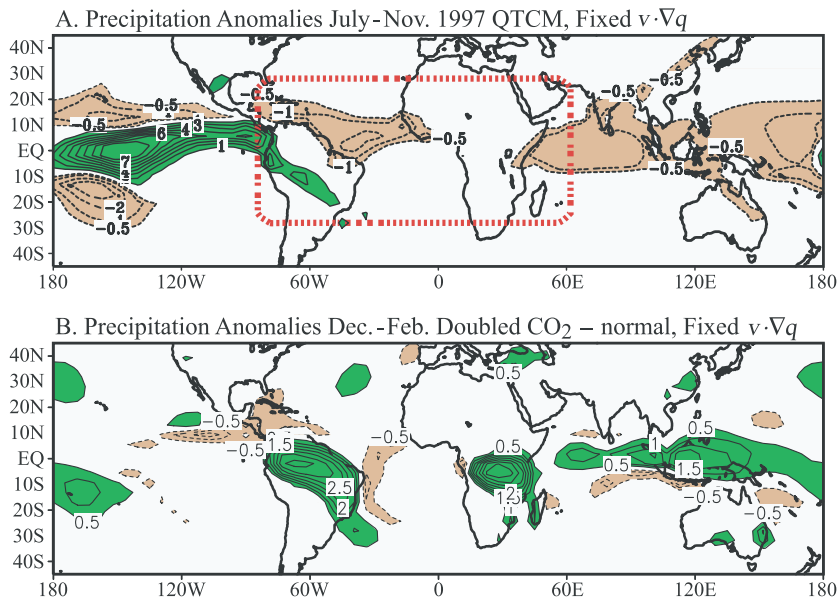

Figure 4. Test of the upped-ante mechanism for regional negative precipitation anomalies in (a), the El Niño case (compare precipitation anomalies to those in Figure 2b) and (b) the doubled- $\mathrm{CO}_{2}$ experiment (compare precipitation anomalies to those in Figure 2c). In each experiment advection of anomalies of moisture are suppressed (see text) in the target region (dashed rectangle) and the whole domain, respectively. 
(Figure 4b), negative precipitation anomalies are very strongly reduced, providing confirmation of the leading importance of the upped-ante mechanism. Additional experiments (not shown) where a tropospheric temperature anomaly is simply inserted in lieu of the full greenhouse radiative calculation confirm that tropospheric warming is indeed the initiator of the mechanism. We also note that in absence of the upped ante mechanism (Figure 4b), positive precipitation anomalies tend to be increased in some regions, suggesting that it acts as a negative tendency over a greater region than that of the negative anomalies, but is overcome by precipitation increase mechanisms deeper into the convection zones. In transient greenhouse gas increase experiments (not shown), the upped-ante mechanism operates similarly to the equilibrium case once warming is well established.

\section{Discussion}

[8] In an intermediate complexity climate model designed for analysis of tropical convective-dynamical pathways, we identify a mechanism for tropical regional drought. This upped-ante mechanism involves the interplay between, on the one hand, a warmed troposphere and the boundary layer moisture required to meet the increased "ante" for convection, and on the other, the effects that horizontal gradients in moisture thus induced have upon moisture transport. We provide evidence that this mechanism is the leading player in producing tropical negative precipitation anomalies in doubled- $\mathrm{CO}_{2}$ coupled atmosphere, mixed-layer ocean experiments.

[9] The upped-ante drought tendency depends on precise gradient of moisture between precipitating and dry regions and the angle of this to the prevailing winds. The regional distribution of this thus represents a subtle quantity for climate models to reproduce. Combining this with the competition between the upped-ante mechanism and mechanisms tending to increase precipitation, it is not surprising that climate models exhibit different regional patterns of tropical drought.

[10] Overall, we argue that progress in predicting tropical regional precipitation anomalies under global warming requires clearer theory for mechanisms. The results here suggest that tropical regional drought under large-scale warming may be considered as a coherent phenomenon. The upped-ante mechanism is put forward as a leading mechanism for these droughts and so may be used in the design of observational strategies. Because this drought mechanism is among those operating in the El Niño interannual variability case, this appears to offer a feasible testing ground for the improvement of models and validation of mechanisms for the global warming case.

[11] Acknowledgments. This work was supported under National Science Foundation grant ATM-0082529, National Oceanic and Atmospheric Administration grants NA16GP2003 and NA16GP2004, and National Science Council grant NSC91-2111-M-001-002.

\section{References}

Allen, M. R., and W. J. Ingram, Constraints on future changes in climate and the hydrologic cycle, Nature, 419, 224-232, 2002.

Boer, G. J., G. Flato, and D. A. Ramsden, Transient climate change simulation with greenhouse gas and aerosol forcing: Projected climate to the twenty-first century, Clim. Dyn., 16, 427-450, 2000.
Chiang, J. C. H., and A. H. Sobel, Tropical tropospheric temperature variations caused by ENSO and their influence on the remote tropical climate, J. Clim., 15, 2616-2631, 2002.

Dai, A., G. A. Meehl, W. M. Washington, T. M. L. Wigley, and J. M. Arblaster, Ensemble simulation of twenty-first century climate changes: Business-as-usual versus $\mathrm{CO}_{2}$ stabilization, Bull. Am. Meteorol. Soc., 82, 2377-2388, 2001.

Douville, H., F. Chauvin, S. Planton, J.-F. Royer, D. Salas-Mélia, and S. Tyteca, Sensitivity of the hydrological cycle to increasing amounts of greenhouse gases and aerosol, Clim. Dyn., 20, 45-68, 2002.

Giorgi, F., Variability and trends of sub-continental scale surface climate in the twentieth century, Part II: AOGCM simulations, Clim. Dyn., 18, 693-708, 2002.

Hansen, J., et al., Global climate changes as forecast by Goddard Institute for Space Studies three-dimensional model, J. Geophys. Res., 93(D8), 9341-9364, 1988.

Houghton, J. T., et al. (Eds), Climate Change 2001: The Scientific Basis, Chapters 9 and 10, Cambridge Univ. Press, Cambridge, 2001.

Hu, Z.-Z., M. Latif, E. Roeckner, and L. Bengtsson, Intensified Asian summer monsoon and its variability in a coupled model forced by increasing greenhouse gas concentrations, Geophys. Res. Lett., 27(17), $2681-2684,2000$.

Jin, F.-F., Z.-Z. Hu, M. Latif, L. Bengtsson, and E. Roeckner, Dynamical and cloud-radiation feedbacks in El Niño and greenhouse warming, Geophys. Res. Lett., 28(8), 1539-1542, 2001.

Johns, T. C., et al., Anthropogenic climate change for 1860 to 2100 simulated with the HadCM3 model under updated emissions scenarios, Clim. Dyn., 20, 583-612, 2003.

Knutson, T. R., and S. Manabe, Time-mean response over the tropical Pacific to increased $\mathrm{CO}_{2}$ in a coupled ocean-atmosphere model, J. Clim., 8, 2181-2199, 1995 .

Meehl, G. A., and W. M. Washington, El Niño-like climate change in a model with increased atmospheric $\mathrm{CO}_{2}$ concentrations, Nature, 382, 5660, 1996.

Mitchell, J. F. B., T. C. Johns, M. Eagles, M. W. J. Ingram, and R. A. Davis, Toward the construction of climate change scenarios, Clim. Change, 41, 547-581, 1999 .

Neelin, J. D., and N. Zeng, A quasi-equilibrium tropical circulation modelFormulation, J. Atmos. Sci., 57, 1741-1766, 2000.

Roeckner, E., L. Bengtsson, J. Feichter, J. Lelieveld, and H. Rodhe, Transient climate change simulations with a coupled atmosphere-ocean GCM including the tropospheric sulfur cycle, J. Clim., 12, 3004-3032, 1999.

$\mathrm{Su}$, H., J. D. Neelin, and C. Chou, Tropical teleconnection and local response to SST anomalies during 1997-1998 El Niño, J. Geophys. Res., 106(D17), 20,025-20,043, 2001.

$\mathrm{Su}, \mathrm{H}$., and J. D. Neelin, Teleconnection mechanisms for tropical Pacific descent anomalies during El Niño, J. Atmos. Sci., 59, 2682-2700, 2002.

$\mathrm{Su}, \mathrm{H}$., and J. D. Neelin, The scatter in tropical average precipitation anomalies, J. Clim., 16, 3966-3977, 2003.

Tett, S. F. B., J. F. B. Mitchell, D. E. Parker, and M. R. Allen, Human influence on the atmospheric vertical temperature structure: Detection and observations, Science, 274, 1170-1173, 1996.

Timmermann, A., J. Oberhuber, A. Bacher, M. Esch, M. Latif, and E. Roeckner, Increased El Niño frequency in a climate model forced by future greenhouse warming, Nature, 398, 694-697, 1999.

Wallace, J. M., T. P. Mitchell, E. M. Rasmusson, V. E. Kousky, E. S. Sarachik, and H. von Storch, On the structure and evolution of ENSOrelated climate variability in the tropical Pacific: Lessons from TOGA, J. Geophys. Res., 103(C7), 14,241-14,259, 1998.

Williams, K. D., C. A. Senior, and J. F. B. Mitchell, Transient climate change in the Hadley Centre Models: The role of physical processes, J. Clim., 14, 2659-2674, 2001.

Xie, P., and P. A. Arkin, Global precipitation: A 17-year monthly analysis based on gauge observations, satellite estimates, and numerical outputs, Bull. Am. Meteorol. Soc., 78, 2539-2558, 1997.

Yonetani, T., and H. B. Gordon, Simulated changes in the frequency of extremes and regional features of seasonal/annual temperature and precipitation when atmospheric $\mathrm{CO}_{2}$ is doubled, J. Clim., 14, 1765-1779, 2001.

Zeng, N., J. D. Neelin, K.-M. Lau, and C. J. Tucker, Enhancement of interdecadal climate variability in the Sahel by vegetation interaction, Science, 286, 1537-1540, 1999.

Zeng, N., J. D. Neelin, and C. Chou, A quasi-equilibrium tropical circulation model-implementation and simulation, J. Atmos. Sci., 57, 17671796, 2000.

C. Chou, Institute of Earth Sciences, Academia Sinica, Taipei 115, Taiwan, ROC. (chia@earth.sinica.edu.tw)

J. D. Neelin and H. Su, Department of Atmospheric Sciences, University of California at Los Angeles, Los Angeles, CA 90095, USA. (neelin@, atmos.ucla.edu; hui@atmos.ucla.edu) 